\title{
Corrientes filosóficas del pensamiento jurídico
}

Ricardo Díaz Bazán

Ph.D. in Administration, Doctor en Derecho.

Decano de la Facultad de Derecho y Ciencias Políticas de la Universidad Alas Peruanas. Docente de pregrado y postgrado.
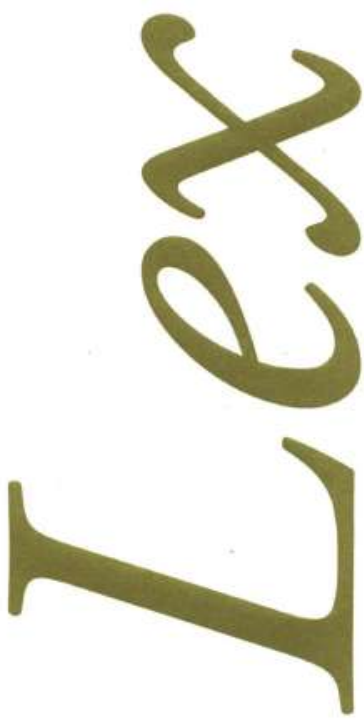


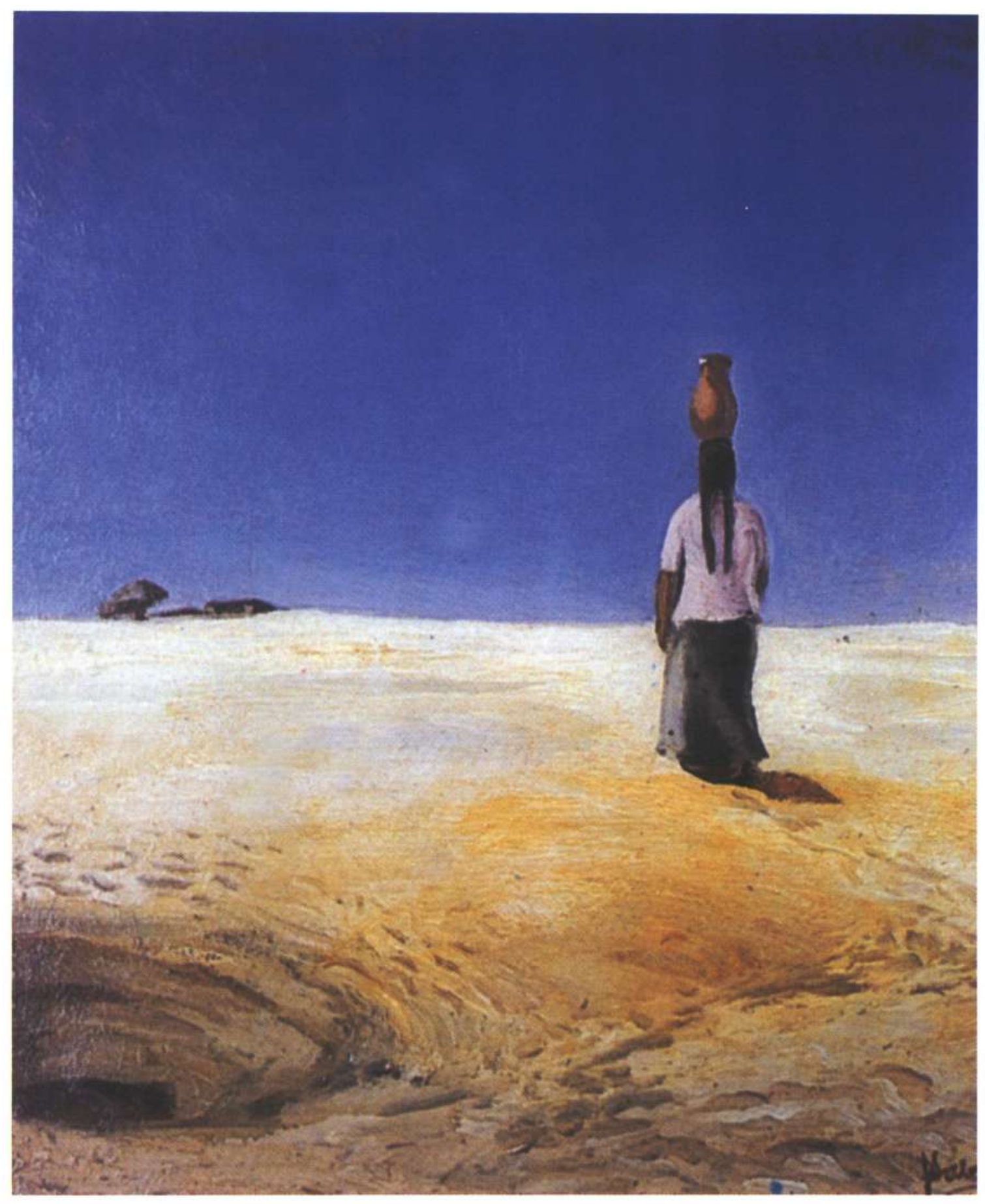

Mujer en el desierto

(Sechura) 


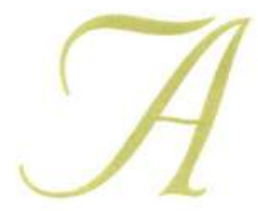

lo largo de la historia, la filosofía jurídica ha desarrollado diversas teorías sobre la naturaleza o el ser del Derecho, las mismas que muchas veces se han superpuesto unas a otras. Y como suele suceder, cada teoría se explica, en parte, por las condiciones sociales e históricas en que apareció y fue desarrollada.

Por ello consideramos necesario hacer una breve exposición de las principales teorías sobre la naturaleza del Derecho, insertadas en los contextos históricos y sociales en los que se dieron.

Entre las principales corrientes filosóficas del pensamiento jurídico podemos mencionar:

\section{Jusnaturalismo}

Es una escuela de pensamiento para la que, por sobre el Derecho positivo -es decir, el Derecho creado por los seres humanos mediante las normas jurídicas que producen o a través de las diversas fuentes del Derecho reconocidas-, existe un Derecho superior (el Derecho natural) compuesto por un conjunto de valores que actúan como inspiración de sus contenidos y como guía de la actuación y decisiones de los agentes del Derecho.

Esta corriente tiene como principal exponente a Santo Tomás de Aquino, quien discierne entre cuatro tipos de leyes:

- La Ley divina, que está en la mente de Dios y no nos es accesible por completo.

- La Ley revelada, que es la parte de la Ley divina comunicada al ser humano a través de las palabras sagradas (texto bíblico).

- La Ley natural, que es la parte de la Ley divina manifestada al hombre a través de su propia observación de la naturaleza, como por ejemplo el derecho a la vida, a la alimentación, a la protección natural, de la familia, etc.

- La Ley positiva o la Ley humana, a la que se llama Derecho positivo. 
El sistema de pensamiento de Santo Tomás es filosófico, pero tiene una evidente y reconocida fundamentación teológica. Su coherencia e importancia son relevantes, útiles aún hoy día, pero suponen en lo esencial un prepuesto de fe que permite el uso de axiomas no discutibles por dicha razón. Esta corriente se desarrolló en tres etapas:

El Jusnaturalismo Grecorromano

El Jusnaturalismo Cristiano

La Escuela Moderna del Derecho Natural.

\section{El Jusnaturalismo Grecorromano}

Tiene los siguientes exponentes:

Sócrates (489 a.C.) admite que existen normas de validez absoluta cuyo conocimiento lleva a la práctica del bien y de la justicia. El sabio es necesariamente virtuoso. La ciudad y las leyes positivas constituyen realidades éticas que todo hombre debe respetar.

Platón (489 a.C.) contrapone la Ley verdadera a la Ley positiva. La primera es la idea de la Ley, y pertenece al mundo de las ideas; la segunda es una imagen o sombra de aquella. El gobernante debe buscar y contemplar aquella idea; de aquí que los gobernantes deban ser filósofos, y los filósofos, gobernantes.

Aristóteles (384 a.C.), considerado el padre del Derecho natural, señala que el bien consiste en la plena realización de la esencia de un ser; «la Ley suprema» de la moralidad es, pues, esta: realiza la esencia, la naturaleza; lo que es natural es al mismo tiempo lo que es moral, la esencia es inmutable.

Marco Antonio Cicerón (106 a.C.) Afirma que la ciencia del Derecho no nace del conocimiento de la Ley de las Doce Tablas ni de los edictos de los pretores, sino de la filosofía, que tiene como fuente la razón misma y que es común a todos los hombres y a todas las épocas.

Cayo identificó al Derecho natural con el Derecho de gentes reconocido por los romanos de todos los pueblos del mundo.

El Jusnaturalismo Cristiano

La filosofía cristiana se inspiró en el pensamiento griego y en la jurisprudencia romana para crear un sistema de Derecho natural con sentido teológico. 
San Agustín (354 a.C.) fundamenta el orden del recurso en la Ley eterna (Ley aeterna), que significa «razón suprema y voluntad de Dios, que manda reparar el orden natural y prohíbe perturbarlo». Esta Ley es para la naturaleza inanimada "necesidad ciega», y para el hombre, norma de su actividad moral escrita en su conciencia.

Santo Tomás de Aquino (nacido en 1225) afirmaba que el universo se halla gobernado por la Ley eterna, que traduce la voluntad y la sabiduría de Dios, que rige todas las cosas del mundo. Los seres, los inanimados y los vivientes, es decir, las cosas, los animales y el hombre están sometidos a la Ley eterna.

\section{Escuela del Derecho Natural}

Bajo los signos del individualismo, el racionalismo y el naturalismo nació el moderno derecho natural.

HUGO GROCIO (nacido en 1583) es el iniciador de esta escuela. Grocio, en su obra De Iure Belli ac Pacis, define el Derecho natural como el dictado de la recta razón que indica que alguna acción, por su conformidad o disconformidad con la misma naturaleza racional, tiene fealdad y necesidad moral y por consiguiente está mandada o prohibida por Dios, autor de la naturaleza.

Según Hobbes, el hombre no es un ser sociable por naturaleza sino egoísta y malvado. En ese estado vive según su Ley, y en tal situación se asocia con los demás mediante un contrato impuesto por la Ley de la conservación, que es el Derecho natural. De ese pacto nació el Estado, cuya función es proteger a los individuos mediante una voluntad omnipotente que se expresa a través de la Ley positiva.

PUFENDORF (nacido en 1632) fue autor de un sistema ecléctico que recogió todas las doctrinas Jusnaturalistas.

CHISTIAN THOMASIO (nacido en 1655) cree que la fuente del Derecho natural es la "felicidad del individuo", que solo puede lograrse con una vida honesta, digna y justa (honestum, decorum justum).

El más elevado exponente del racionalismo fue Kant. La noción fundamental de la doctrina kantiana sobre el Derecho es la idea de la libertad. La libertad asume dos formas: libertad de arbitrio o «independencia de todo impulso sensible en cuanto a su determinación», que es la 
noción negativa de libertad y la "facultad de la razón pura de ser práctica a sí misma», que es la noción positiva que solo es posible por la sumisión de las máximas de toda acción a la condición de poder servir de Ley general.

\section{Positivismo o formalismo jurídico}

El Positivismo surgió como lógica reacción contra las abstracciones y vaguedades del Jusnaturalismo y como fruto de una necesidad de certeza de los juristas que buscaron apoyo en el método de las ciencias naturales como el único capaz de garantizar un auténtico saber.

Esta corriente inició su ruta hacia la preponderancia en el siglo pasado, y la adquirió en los primeros decenios de este, con Hans Kelsen a la cabeza.

Kelsen plantea que para estructurar una ciencia autónoma del Derecho, hay que separar todo lo que pertenece a otras ciencias, sean propias de la moral, la religión, la sociología o la política. Así, lo propio del Derecho, la teoría "pura del derecho", consistirá en su esencia normativa, la norma jurídica válida y el sistema eficaz que regula efectivamente las conductas de los sujetos y la sociedad en su conjunto.

Empieza por constatar que el Derecho como sistema para regir no tiene que ostentar un cumplimiento rígido ni universal. Basta que la generalidad de sujetos lo acate para que efectivamente sea eficaz y, por tanto, orden jurídico propiamente dicho.

Imagina al Derecho como una pirámide en cuyo vértice existe una norma que lo sostiene como conjunto. Esta norma no es un texto legislativo ni nada semejante, es, más bien, una hipótesis sobre su eficacia; si el orden jurídico en su conjunto es acatado por la generalidad de los sujetos de la sociedad correspondiente, entonces es su orden jurídico, y en caso contrario no lo es. Es fundamental porque así se define.

La vinculación del positivismo con la aparición del Estado moderno es evidente, y en cierta forma constituye la teoría que más cabalmente intenta expresar su altísimo grado de desarrollo y consolidación durante este siglo.

Por ello no es raro que Kelsen identifique al Estado y al Derecho, mostrándolos como las dos caras de la misma moneda: el Derecho es el Estado porque él es el que lo produce. El Estado es el Derecho porque, al fin y al cabo, el Estado es el máximo poder dentro de la sociedad, y el Derecho es el que efectivamente obedece como orden jurídico eficaz, fundado en la norma hipotética fundamental. 
En síntesis, el Positivismo Jurídico ha diseñado la construcción de un modelo de teoría del Derecho válido en sí mismo y que efectivamente ha significado un aporte en términos contemporáneos a la consolidación del Estado moderno y a la mejor comprensión del Derecho. Sin embargo, como concepción integral y excluyente de otras nos parece insuficiente porque el Derecho tiene como finalidad regir mejor a la sociedad y no solo ser una estructura perfecta en sí mismo.

\section{Sociologísmo Jurídico}

Esta corriente sostiene que para interpretar el Derecho hay que proceder a una concienzuda comprensión y a una correcta valoración de las realidades sociales vigentes en determinado momento histórico. Para ello se requiere de un profundo conocimiento sociológico de los hechos, necesidades y vivencias sociales a fin de poder formular normas generales e individuales.

Estima que el Derecho es un fenómeno social que nace y evoluciona en virtud de la acción de los diversos factores de la convivencia colectiva.

\section{Fenomenología}

De acuerdo con las ideas de Edmonel Husserl, la fenomenología jurídica representada por Adolf Reinach (1887-1971), autor de Fundamentos aprioristicos del Derecho Civil, se dirige hacia el objeto del Derecho en su esencia misma, renunciando a construcciones y teorías.

Según la opinión de Reinach, el ser del Derecho no es construido por el Derecho positivo sino que este lo encuentra. Los conceptos jurídicos presentan ciertas estructuras ontológicas innatamente, y a priori es necesaria la presuposición que requiere la elaboración de esos conceptos en el interior de un orden positivo concreto. Estas estructuras constituyen un conjunto de caracteres que deben estar presentes para que un concepto jurídico específico pueda «ser», en tanto que tal: la propiedad, la promesa, la hipótesis, etc.

Presentan una eidética objetiva a priori, independiente de los residuos psicológicos de los sujetos y de las consideraciones axiológicas o de las prescripciones del Derecho positivo.

\section{Raciovitalismo}

Su autor es Luis Recasens Siches, quien siguiendo a su maestro Ortega reafirma que la filosofía busca un punto de partida radical y primario, sin supuestos anteriores, sin dejar atrás 
implicaciones previas no resueltas, esto es, es autónoma. Dentro de estas características, la filosofía del Derecho convierte lo jurídico en problema total, es decir, lo enfoca sin partir de supuestos jurídicos previos.

En la visión de Recasens Siches, el Derecho se inserta en una realidad primaria y radical que es la vida humana. Esta constituye nuestra propia existencia, la de cada uno, todo cuanto hacemos, deseamos, pensamos y nos ocurre.

El Derecho pertenece a este ámbito y «en tanto que en forma objetivada de la vida humana, está constituido por un conjunto de ideas, mejor diríamos significaciones, que constituyen reglas para la conducta humana».

El Derecho se caracteriza, además, por pertenecer al especto de la vida humana que es lo normativo -señala lo que debe ser y no lo que es o será- y su aspecto colectivo, porque es un quehacer social.

Como producto de la cultura, el Derecho es norma elaborada para la realización de valores. Por esta razón, sus tres dimensiones -valor, norma, hecho- se dan indisolublemente unidas «en relación esencial de implicación». El Derecho no es un valor puro. El Derecho es una obra humana social con notas particulares.

El Derecho es una obra humana social (hecho) de forma normativa encaminada a la realización de unos valores.

\section{Escuela Egológica}

Elaborada por el profesor argentino Carlos Cossío, la teoría egológica sitúa al Derecho en el mundo de la cultura de acuerdo con la filosofía husserliana. Cossío agrupa los objetos en cuatro regiones: los objetos ideales, los objetos naturales, los objetos culturales y los metafísicos.

Los objetos culturales se caracterizan frente a los objetos ideales porque aquellos son reales, frente a los naturales porque son valiosos, y frente a los metafísicos porque están sujetos a la experiencia, ya que son en el tiempo.

En el ámbito de los objetos culturales cabe distinguir, según esta teoría, los objetos mundanales, que son vida humana objetiva cuyo sustrato es independiente del hombre, y los objetos egológicos, cuyo sustrato es la conducta como vida biográfica. El Derecho es objeto egológico. 
En este sentido, el Derecho no se define como un conjunto de comparamiento sino como "vida humana viviente», como la conducta misma; o para emplear la fórmula completa de la teoría egológica, como "la conducta humana considerada en su interferencia intersubjetiva», que tiene por esencia la libertad.

Las normas jurídicas son para Cossío conceptos con los cuales nos representamos o pensamos intelectualmente la conducta, y como tales son instrumentos para conocerla. "No se conoce a las normas, dice, sino que se conoce con las normas a la conducta como conducta».

Las normas jurídicas, como se ha visto antes, son para esta teoría juicios disyuntivos, permanecen ajenos a toda valoración, aunque mientan objetos valiosos, no como cualidades de la norma misma sino de la conducta mentada.

Pero la norma no solo juega con ese papel, sino con otro dentro de esta doctrina. No solo realiza la mención conceptual del objeto sino que además «forma parte del sentido del objeto que ella misma mienta». En términos más claros aún, «la norma integra el objeto de que ella misma hace mención", puesto que ese objeto es objeto cultural, y como tal, tiene un sentido que al ser vivenciado por la norma queda integrando el propio objeto del que ella hace mención.

Los valores del Derecho constituyen un plexo axiológico al que apunta la conducta humana.

Los ejes de esta teoría se ponen de manifiesto sobre todo en la ubicación del Derecho en la región de los objetos culturales y en la definición del Derecho como conducta e interferencia intersubjetiva.

La teoría egológica distingue dos clases de objetos culturales: los mundanales y los objetos egológicos (de ego: yo), los cuales tienen por sustrato la conducta humana.

Para esta teoría, la conducta humana es un hacerse a sí mismo cada día, y no una realidad terminada y definitiva. De aquí se deduce que la conducta es también un objeto cultural en cuanto la constituye el hombre, pero posee un carácter y un sentido distinto al de los objetos mundanales (producto de la actividad humana).

En la teoría egológica, la vinculación entre derecho y conducta queda de manifiesto en la misma definición. El derecho es la conducta de interferencia intersubjetiva.

El Derecho aparece contenido en la conducta convertida ahora en objeto de conocimiento jurídico. El Derecho no es producto de la razón ni se origina en las normas sino que se da en la 
experiencia y se manifiesta como conducta humana. Es una experiencia de libertad, distinta de la experiencia de necesidad, que se regula por la ley. Esto significa que el hombre frente a las normas de derecho actúa con una actitud favorable o desfavorable, como consecuencia del uso de su libertad, por lo cual la conducta y no la norma es la que interesa a la teoría egológica.

Para que una conducta interese al Derecho, debe tener las siguientes características:

a) Ser una interferencia, que aquí significa una acción en la cual el hombre es el sujeto único en un determinado comportamiento. Se trata de una interferencia que afecta a las posibles conductas personales, en una interferencia subjetiva, que para esta teoría pertenece exclusivamente al plano de la moral.

b) Este tipo de interferencia no basta; sin embargo, puede caracterizar una conducta jurídica, ya que crea alteridad, es decir, una relación entre dos o más personas.

c) De esta característica se desprende que la conducta jurídica es necesariamente social. La concepción de la norma como representación o instrumento para conocer la conducta jurídica lleva a esta teoría a sostener que el Derecho no está en la ley, ni en las sentencias judiciales, ni en las normas. Se encuentra, por el contrario, en la conducta que como vida se expresa en las normas, en la ley y en las sentencias.

\section{Tridimensionalismo}

Es una de las teorías contemporáneas que ofrecen nuevos elementos para la construcción del ordenamiento jurídico, concibiendo el Derecho en todos los casos como norma, hecho y valor.

Los principales intentos para aclarar e integrar de una manera sistemática las tres dimensiones del Derecho: hecho, norma y valor, tienen lugar a partir del año 1940. Esa integración exige analizar el Derecho a partir de las disciplinas que justifican y explican la norma, el hecho y el valor en el Derecho.

Puede hacerse, entonces, las siguientes consideraciones:

a) El Derecho es norma, pues aparece prescribiendo o prohibiendo una determinada conducta.

b) $\mathrm{Al}$ mismo tiempo surge a pertenecer a una realidad concreta y se ha de aplicar a ella; el Derecho es aquí un hecho social vinculado a los demás fenómenos sociales. 
c) Por último, el Derecho realiza una serie de valores -orden, seguridad, paz-como condiciones previas para imponer la justicia.

\section{El tridimensionalismo y la experiencia jurídica}

Presencia del pensamiento jusfilosófico latinoamericano

El mundo latinoamericano, de pujante potencialidad creadora, contribuye con un pensamiento remozado y de acuerdo con su realidad a la evolución del pensamiento jurídico contemporáneo. No hay exageración en lo expresado si nos atenemos a las frescas y originales formulaciones jusfilosóficas tanto de la escuela egológica como del tridemensionalismo jurídico, que, aproximándose desde vecinas perspectivas a una filosofía de la existencia, fijan su atención en el fenómeno jurídico tal como se nos aparece, para resaltar en él tanto el rol protagónico de la conducta humana intersubjetiva como la compleja integración dinámica en que consiste la unitaria realidad del Derecho, respectivamente.

El jurista contemporáneo al sustentar su tarea científica en los supuestos que vienen dados por la jusfilosofía, se enfrenta a un mundo convulso y angustiado, ahíto de injusticias y desigualdades sustanciales. Jaqueado por esta acuciante realidad, comprende, con el correr de las décadas, que es necesario despojar a la dogmática jurídica, ahí donde sea menester, de visiones que, por unilaterales y parciales, le impiden contemplar en su dinámica unidad la compleja totalidad del Derecho, en la cual la persona adquiere un rol protagónico.

El aporte de la Escuela Egológica del Derecho

En el esfuerzo para revalorizar el rol protagónico de la persona en el Derecho destaca, en contraprestación al pensamiento formalista de corte kelseniano, el original aporte de la llamada Escuela Egológica del Derecho, que fructifica en Argentina a partir de la década del cuarenta. El egologismo, que se enraíza preponderantemente en la fenomenología husserliana y en la filosofía de la existencia, adquiere rápida difusión y es acogido con interés por los estudiosos de la ciencia jurídica.

La escuela egológica del Derecho es fruto del original pensamiento del jusfilósofo argentino Carlos Cossío, quien, sin negar la presencia actuante tanto de los valores como de las normas jurídicas en la experiencia, sostiene que ambos elementos se integran en unidad inescindible en la conducta humana. Es así que la conducta humana intersubjetiva se erige en el objeto propio de la ciencia jurídica, en el objeto de conocer por los juristas. 
Para llegar a dicha conclusión, Cossío parte de los postulados de la filosofía de la existencia y del pensamiento de Husserl y Dilthey, aparte de la preocupación epistemológica de raíz kantiana. Su propósito es superar las posiciones tanto de la escuela del Derecho natural como las del formalismo jurídico, que constituían a los valores y a las normas como los objetos propios de la ciencia del Derecho, respectivamente. La tesis cossiana reduce el Derecho a la conducta humana intersubjetiva, la que se muestra como expresión fenoménica de la libertad.

La teoría egológica tiene el indiscutible mérito de resaltar el rol central que ocupa la vida humana social dentro de la experiencia jurídica, aunque esta actitud la lleve a propugnar un reductivismo que no se condice con la realidad.

Su sustento de raigambre filosófica impide confundir a la egología con los postulados del sociologismo jurídico, pese a contener algunos aspectos que les son comunes. La escuela egológica está signada por una visión ontológica del Derecho, el mismo que resulta ser una experiencia fenoménica de libertad.

La polémica actitud asumida por Cossío, y que para algunos tiene un excesivo afán proselitista, coadyuvó probablemente a que ciertos autores reaccionaran adversamente frente a su novedosa teoría. Ello motivó que tales juristas minimizaran injustificadamente su aporte. No obstante los errores que, como todo planteamiento jusfilosófico, encierra la teoría egológica, especialmente en cuanto al aspecto lógico se refiere, es justo resaltar su valiosa y original contribución a la filosofía del Derecho en un momento en que el pensamiento formalista era del todo hegemónico.

La escuela egológica recogió adhesiones y elogios en diversas latitudes, donde se supo apreciar la originalidad y el vigor de sus postulados.

\section{El tridimensionalismo Jurídico}

\section{Antecedentes}

Como certeramente lo advierte Miguel Reale, se observa, en especial a partir de la segunda postguerra, una aspiración generalizada hacia la comprensión global y unitaria de los problemas jurídicos, abandonando las predilecciones reduccionistas que llevan a planteamientos pseudototalizadores. Por ello no son pocos los jusfilósofos que muestran una tendencia a resaltar tres elementos o factores que se hallan presentes en la experiencia jurídica, como son la conducta humana, las normas y los valores jurídicos. 
El tridimensionalismo surge en un primer momento como la comprobación objetiva que realizan en la experiencia jurídica algunos pocos jusfilósofos de la existencia de los tres elementos antes indicados pero sin que tal verificación signifique llegar a encontrar entre ellos un específico tipo de relación esencial. Para dichos filósofos del Derecho, las mencionadas perspectivas constituían solo elementos separables e independientes. No se planteaba aún, en este inicial momento, una teoría integradora de los mismos. Reale designa a esta modalidad del tridimensionalismo como "genérico y abstracto".

Miguel Reale ha efectuado una revisión histórica y crítica del pensamiento de los autores que adhieren a esta precursora instancia del tridimensionalismo, así como ha planteado y desarrollado el tridimensionalismo en su segunda etapa. En esta última se elabora, se consolida un tridimensionalismo diferente, integrador y dinámico, específico y concreto, que profesan tanto dicho autor como el que escribe este artículo.

Reale considera a Lask y Radbruch como los pensadores que intentaron superar «la antinomia suscitada entre la ahistoricidad de un valor trascendente (del que el jusnaturalismo había pretendido deducir artificialmente todo el sistema de normas positivas) y el mero significado contingente de las relaciones de hecho, no susceptibles de comprensión de validez universal, como sustentaban los positivistas.

En estos autores se advierte un reconocimiento de la realidad triádica del Derecho, pero su visión es aún estática en el sentido de que conciben a dichos elementos como objetos separados e independientes, a cada uno de los cuales corresponde un método y un orden particular de conocimientos.

Al lado de estos autores y en el área del pensamiento jusfilosófico alemán, Reale señala también dentro de esta orientación a Fechner y Welzel, cuya posición arraiga en una filosofía de la existencia.

En Italia encuéntranse algunos autores que pueden ser considerados como tridimensionalistas, dentro de un planteamiento que continúa siendo genérico y abstracto.

En las obras de Vanni, del Vecchio, Bobbio se admite la presencia en el Derecho de tres perspectivas, pero dentro de un esquema en el cual dichos elementos aparecen como objetos separables y no integrados dinámica y esencialmente. La aparición de tales autores, como lo resalta Reale, es meramente didáctica, en cuanto se realiza en función de las tareas sectoriales que corresponden a la filosofía del Derecho, pero sin incidir en la estructura misma de lo jurídico. 
Norberto Bobbio, en el sentido antes señalado, destaca las diversas funciones que en el estudio de las diversas perspectivas del Derecho competen a la filosofía del Derecho, a la sociología jurídica y a la teoría general del Derecho, respectivamente.

En Francia, se señala a Paul Roubier como el importante jusfilósofo que a través de sus planteamientos permite el desarrollo de un pensamiento que descubre, aunque de modo abstracto y genérico, la tridimensionalidad del Derecho. Entre sus discípulos se encuentran Lamand y Virally.

En el área del Common Law cabe citar los nombres de Julius Stone y Joseph Kunz. El primero de los nombrados desarrolla un discurso que puede seguir siendo catalogado como abstracto y genérico, en la medida que separa cada uno de los diversos elementos de la experiencia jurídica para tratarlos aisladamente, sin encontrar aún en ellos una esencial y unitaria integración.

En el mundo de habla castellana destacan por su tridimensionalismo los egregios nombres de Luis Legaz y Lagambra, Eduardo García Maníes y Luis Recasens Siches, quien se adhirió a esta posición luego de conocer la obra de Reale.

En su libro La definición del Derecho, García Maynez explicita una posición conocida como perspectivismo jurídico, en la cual cada una de las tres dimensiones de la experiencia jurídica se yuxtapone como una diversa perspectiva de lo jurídico. Se trata de tres diferentes objetos que no constituyen, por tanto, especies de un mismo género.

Es interesante comprobar la notoria evolución que se produce en el pensamiento tanto de Luis Legaz y Lacambra como en el de Luis Recasens Siches, autores que han ejercido notable influencia en los juristas del mundo iberoamericano.

El pensamiento de ambos autores se desarrolla desde posiciones no definidamente tridimensionalistas hacia una concepción integradora del Derecho. Legaz y Lacambra percibe con claridad las dos dimensiones estructurales de la persona humana, como son la vida personal y aquella social.

Tal vez fue Recasens Siches el que con más entusiasmo y convicción acogió los planteamientos del tridimensionalismo expuestos por Reale. Influenciado por el raciovitalismo orteguiano, Recasens Siches en su extraordinario libro Vida humana, sociedady Derecho, después de efectuar un recorrido de connotación existencial, concluye definiendo al Derecho como vida humana objetivada, es decir, como normatividad producto de vivencias culturales. En un segundo momento, arriba a un perspectivismo genérico y abstracto al reconocer que la realidad que constitu- 
ye el Derecho y posee la dimensión de referirse a valores tiene forma normativa. Es decir, el Derecho es norma con especiales características elaboradas por los hombres con el propósito de poner en práctica ciertos valores.

Como vemos, cada escuela jusfilosófica nos deja una perspectiva de lo que es el Derecho y de los fines que persigue para alcanzar el fin supremo de la justicia.

\section{Bibliografía}

Brugger W. Diccionario de filosofia. Alemania, 1962.

Baudin. Curso de filosofia moral. Francia, 1974.

Batifol. Filosofia del Derecho. Francia, 1970.

Dworkin. Filosofia del Derecho. Inglaterra, 1981.

Del Vecchio. Filosofia del Derecho. Italia, 1980.

Gonzales Ireneo. Filosofia moral. España, 1965.

Hume. Tratado de naturaleza moral. 1971.

Lugo. Justicia y Derecho. 1968.

Liberatore. Ética y Derecho natural.

Ortega y Gasset. Qué son los valores. 


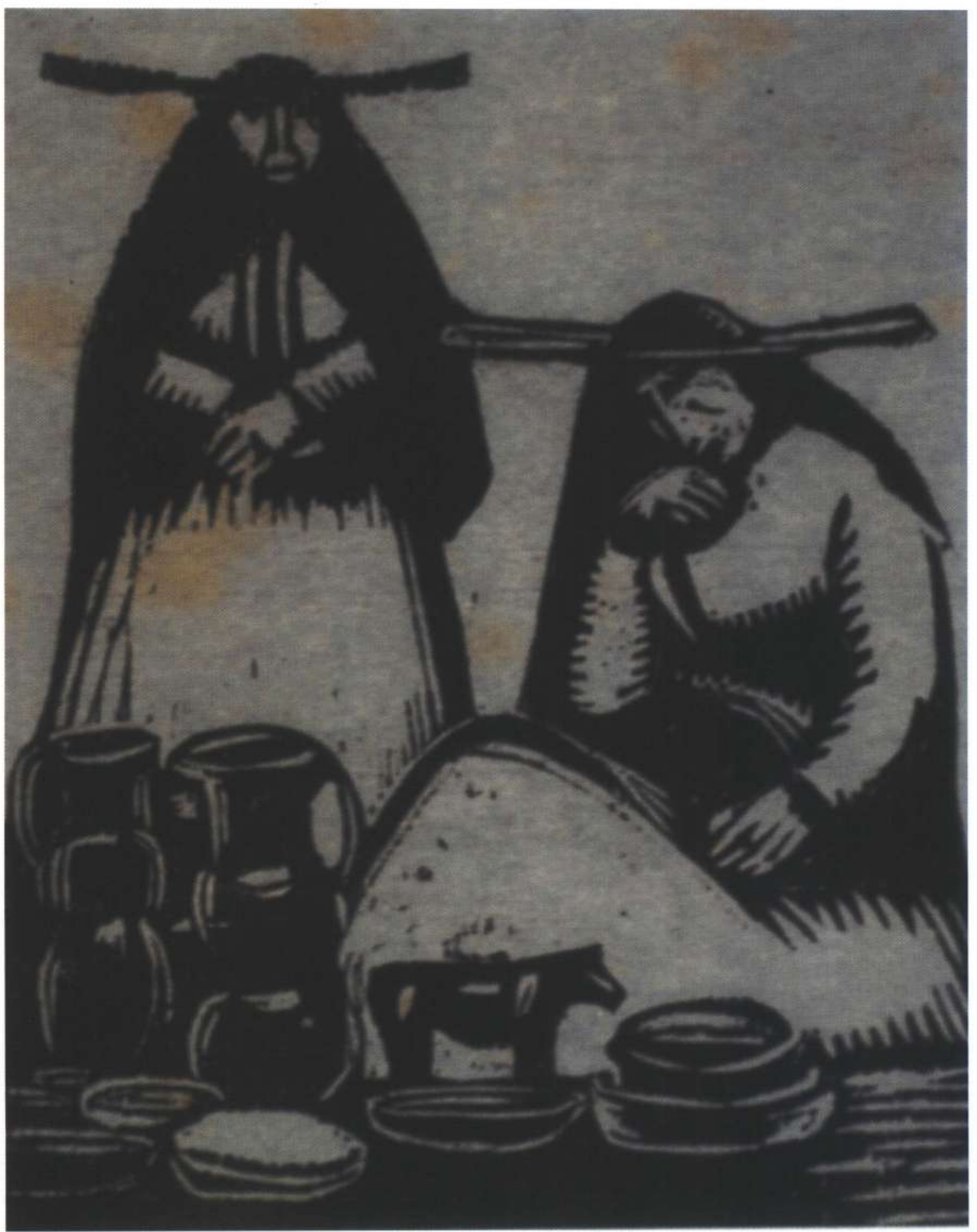

Cacharreras 